\title{
Sodium Restriction Counseling Reduces Cardiac Events in Patients With Heart Failure
}

\author{
Takafumi Nakajima, MD; Makoto Murata, MD, PhD; Syogo Nitta; \\ Tatsunori Shitara; Hiroko Kazama; Yukiko Satoh; Masayo Takizawa; \\ Akemi Mori; Yasuyuki Kobayashi; Hitoshi Adachi, MD, PhD
}

\begin{abstract}
Background: Many heart failure (HF) guidelines recommend sodium restriction for patients with HF, but the outcome of sodium restriction counseling (SRC) for HF patients is still unknown. We wanted to clarify whether SRC reduces cardiac events in patients with HF.

Methods and Results: Overall, 800 patients ( $77 \pm 12$ years) who were hospitalized for HF were enrolled. During HF hospitalization, patients received SRC; patients were required to have a salt intake of $<6 \mathrm{~g} /$ day. After discharge, death or HF rehospitalization events were investigated. During a mean follow-up of $319 \pm 252$ days, 83 patients died, and 153 patients were rehospitalized for HF. SRC significantly decreased all-cause death (odds ratio, $0.42 ; 95 \%$ confidence interval [CI], 0.23-0.76; $\mathrm{P}<0.01$ ), especially cardiac death of hospitalized HF patients after discharge. In the multivariate analysis adjusted for age, sex, SRC, body mass index, hypertension, dyslipidemia, $\beta$-blockers, and mineralocorticoid receptor antagonist intake, cardiac rehabilitation, and the type of HF, SRC remained a significant predictor of death. Kaplan-Meier analysis showed that SRC significantly reduced deaths and the combined outcome of HF rehospitalization and death. In patients with reduced left ventricular ejection fraction, SRC significantly decreased the mortality rate (odds ratio, $0.27 ; 95 \% \mathrm{Cl}, 0.10-0.71 ; \mathrm{P}<0.01$ ).
\end{abstract}

Conclusions: SRC reduced the mortality rate after discharge of hospitalized HF patients.

Key Words: Heart failure; Low-sodium diet; Mortality; Nutrition therapy; Sodium restriction counseling

$\mathbf{T}$ he incidence of heart failure (HF) is increasing worldwide, 1,2 and the 1-year mortality and HF rehospitalization rates are significantly high. ${ }^{36}$ Therefore, new therapies are needed to reduce both the number of HF patients and their deaths after discharge.

Sodium restriction is a major and classical nutrition therapy for patients with HF; most of the major HF guidelines recommend sodium restriction. ${ }^{7-9}$ However, compared with $\beta$-blockers, angiotensin coenzyme inhibitors (ACEI) (angiotensin II receptor blockers [ARB]), and mineralocorticoid receptor antagonist (MRA) medications for $\mathrm{HF}$, the evidence for sodium restriction therapy efficacy is still limited. ${ }^{7}$

In Japan, nutrition therapy is clinically performed by registered dietitians as sodium restriction counseling (SRC) for patients with HF. However, reports on SRC outcomes are rare. We hypothesized that SRC reduces HF rehospitalization or death after hospitalization of patients with HF.

\section{Editorial p1563}

\section{Methods}

\section{Patients and Study Design}

The study recruited 800 consecutive patients with HF who were hospitalized between 2018 and 2019 at the Gunma Prefectural Cardiovascular Center. After excluding patients who died during hospitalization, 743 patients who were discharged were enrolled.

$\mathrm{SRC}$ was conducted by professional nutritionists (registered dietitians) to help HF patients reduce salt intake to $<6 \mathrm{~g} /$ day after discharge. The counseling session was held once during HF hospitalization, and session lasted at least $30 \mathrm{~min}$. Patients were followed up after discharge to record any deaths or HF rehospitalization events, which were analyzed as outcomes, together with the combined outcome of with or without SRC.

Received December 3, 2020; revised manuscript received April 2, 2021; accepted April 21, 2021; J-STAGE Advance Publication released online June 22, 2021 Time for primary review: 25 days

Department of Cardiology (T.N., M.M., H.A.), Department of Rehabilitation (S.N., T.S., H.K.), Nutrition and Cooking Division (Y.S., M.T., A.M.), Department of Physiological Examination (Y.K.), Gunma Prefectural Cardiovascular Center, Maebashi, Japan

Mailing address: Makoto Murata, MD, PhD, Department of Cardiology, Gunma Prefectural Cardiovascular Center, 3-12 Kameizumimachi, Maebashi 371-0004, Japan. E-mail: yarukimanmann2000@yahoo.co.jp

All rights are reserved to the Japanese Circulation Society. For permissions, please e-mail: cj@j-circ.or.jp

ISSN-1346-9843 


\section{Transthoracic Echocardiography}

Transthoracic echocardiographic data were obtained by an experienced sonographer according to the guidelines reported by Nakatani et al. ${ }^{10,11} \mathrm{GE}$ vivid E9 equipped with a $1.75-3.5 \mathrm{MHz}$ transducer was used for the evaluation. Left ventricular ejection fraction (LVEF) was calculated using the modified Simpson's rule. According to the LVEF, the type of $\mathrm{HF}$ was classified as: $\mathrm{HF}$ with reduced $\mathrm{EF}$ (HFrEF:LVEF<40\%), HF with preserved EF (HFpEF: $\mathrm{LVEF} \geq 50 \%$ ), and HF with mid-range EF (HFmrEF: $40 \% \leq \mathrm{LVEF}<50 \%$ ).

\section{Cardiopulmonary Exercise Test (CPET) Protocol and Data Collection}

The CPET parameters were evaluated during symptomlimited exercise using a mask, an upright cycle ergometer (Strength Ergo 8; Mitsubishi Electric Engineering, Tokyo, Japan), and ECG equipment (ML-9000; Fukuda Denshi Ltd., Tokyo, Japan). CPET was performed 2-4h after the patient had consumed a light meal, beginning with $3 \mathrm{~min}$ of rest and $3 \mathrm{~min}$ of warm-up exercise at $0 \mathrm{~W}$, followed by a continuous increase in work rate (WR) by $1 \mathrm{~W}$ every $6 \mathrm{~s}$ until exhaustion, as recommended by Buchfuhrer et al. ${ }^{12}$ Exhaustion was defined as a gas exchange ratio (carbon dioxide production/oxygen consumption $\left[\dot{\mathrm{V} C \mathrm{C}_{2}} / \dot{\mathrm{VO}}_{2}\right]$ ) of $>1.10$ or a score of 20 points for leg exhaustion on the Borg scale. ${ }^{13}$ Relevant parameters $\left(\dot{\mathrm{VO}}_{2}, \dot{\mathrm{V} C O}\right.$, and minute ventilation [ $\mathrm{VE}]$ ) were measured on a breath-by-breath basis using a gas analyzer (MINATO 300S; Minato Science Co. Ltd, Osaka, Japan).

Anaerobic threshold was measured using the V-slope method. ${ }^{14}$ Peak $\dot{\mathrm{VO}}_{2}$ was defined as the $\dot{\mathrm{VO}}_{2}$ at peak WR during exercise. The $\dot{\mathrm{VE}}$ vs. $\dot{\mathrm{VCO}} 2$ slope was defined as the slope of the linear regression line describing the behavior of $\mathrm{VE}$ during incremental exercise up to the respiratory compensation point on the plot of $\mathrm{VE}$ as a function of $\dot{\mathrm{V} C O}{ }_{2 .}{ }^{15}$ All CPET parameters were evaluated by consensus among 3 cardiologists.

\section{Estimation of Sodium Intake}

Spot urine tests were performed on admission day and after the first outpatient clinic visit (1-2 months after discharge). Data were obtained for $13 \%$ of all participants. Estimated salt intake (g/day) was calculated using Tanaka's formula: ${ }^{16}$ estimated salt intake $(\mathrm{g} /$ day $)=21.98 / 17 \times[$ sodium $(\mathrm{mEq} / \mathrm{L}) /$ creatine $(\mathrm{mg} / \mathrm{dL})$ in the spot urine $/ 10 \times 24-\mathrm{h}$ estimated creatine excretion (mg/day) $]^{0.392}$ and, 24-h estimated creatine excretion $(\mathrm{mg} /$ day $)=$ body weight $(\mathrm{kg}) \times 14.89+$ height $(\mathrm{cm}) \times 16.14-$ age $\times 2.043-2,244.45$.

\section{Transtheoretical Model (TTM)}

The patients' behavioral stage data were collected using a questionnaire and evaluated by the TTM model. ${ }^{17}$ The TTM is divided into 5 stages: "pre-contemplation" (no intention of salt restriction); "contemplation" (intention for salt restriction but not prepared for salt restriction); "preparation" (prepared for salt restriction after discharge); "action" (showing salt restriction behavior within 6 months); and "maintenance" (continuing salt restriction behavior for $>6$ months). The patients were divided into 2 groups: "non-active stage," which included the pre-contemplation, contemplation and preparation stages, and the "active stage," which included the action and maintenance stages.

\section{Follow-up After Discharge}

Hospital records of regular check-ups after discharge of the HF patients were investigated. Mortality was defined as death due to any cause; cardiovascular (CV) death owing to HF, myocardial infarction (MI), cerebrovascular disease, and sudden death. HF hospitalization was defined as major symptoms (breathlessness, orthopnea, fatigue, and ankle swelling) and signs (elevated jugular venous pressure, hepatojugular reflux, 3rd heart sound, and laterally displaced apical impulse) of $\mathrm{HF}^{7}$ in patients hospitalized to receive intravenous therapy (diuretics, catecholamines, or carperitide).

\section{Statistical Analysis}

Statistical analyses were performed using the Statistical Package for Social Sciences version 20 (IBM Corp., Armonk, NY, USA). All data are expressed as mean \pm standard deviation, median (25-75th percentiles), or frequency (percentage). Quantitative data were analyzed using Student's t-test, the paired t-test, chi-square test, or Mann-Whitney $\mathrm{U}$ test as appropriate. Univariate and multivariable logistic analyses and Kaplan-Meier analysis were used for identifying predictors of death, HF rehospitalization, and the combined outcomes. Statistical significance was defined as $\mathrm{P}<0.05$.

\section{Ethical Considerations}

The study was conducted according to the Declaration of Helsinki and approved by the Ethics Committee of the Gunma Prefectural Cardiovascular Centre (no. 2020015).

\section{Results}

\section{Baseline Clinical Characteristics, Mortality, and HF Events}

The patients' characteristics are summarized in Table 1. The mean age was $77 \pm 12$ years, and $58 \%$ of the patients were male. The percentage of $\mathrm{HFpEF}, \mathrm{HFmrEF}$, and HFrEF was $44 \%, 14 \%$, and $42 \%$, respectively. The mean LVEF was $45.5 \pm 19.2 \%$, and peak $\dot{\mathrm{VO}}_{2}$ was $13.2 \pm 3.5 \mathrm{~mL} / \mathrm{min} / \mathrm{kg}$. SRC was given to $31 \%(n=230)$ of the participants. Patients undertaking SRC were younger; had a higher body mass index (BMI); had HFmrEF, hypertension, and dyslipidemia; and participated in cardiac rehabilitation after discharge.

Patients were followed up for $319 \pm 252$ days (median, 295 days; 25 th percentile, 83 days; 75 th percentile, 503 days), during which 83 patients died (66 CV deaths: $53 \mathrm{HF}$, 3 MI, 10 sudden deaths), and 153 were rehospitalized because of HF.

\section{SRC With Mortality and HF Events}

Patients who underwent SRC had significantly lower allcause death (odds ratio [OR], $0.42 ; 95 \%$ confidence interval $[\mathrm{CI}], 0.23-0.76 ; \mathrm{P}<0.01)$ and cardiac death $(\mathrm{OR}, 0.33 ; 95 \%$ CI, 0.16-0.68, $\mathrm{P}<0.01)$ than patients who did not undertake SRC; however, rehospitalization owing to HF and combined events of death and HF rehospitalization were not significant (Table 2). Kaplan-Meier analysis showed that SRC significantly reduced deaths (log-rank $\mathrm{X}^{2}, 11.159$; $\mathrm{P}<0.01)$ and the combined outcome of HF rehospitalization and death (log-rank $\left.\mathrm{X}^{2}, 4.792 ; \mathrm{P}=0.03\right)$ (Figure 1).

\section{Relationship of SRC With Mortality and HF Events}

The results of the univariate and multivariate analyses for the variables of death are summarized in Table 3. After adjustment for age, sex, SRC, BMI, hypertension, dyslip- 


\begin{tabular}{|c|c|c|c|c|}
\hline & $\begin{array}{l}\text { Overall } \\
(n=743)\end{array}$ & $\begin{array}{l}\text { SRC (+) } \\
(n=229)\end{array}$ & $\begin{array}{l}\text { SRC (-) } \\
(n=514)\end{array}$ & $P$ value \\
\hline Age, years & $77 \pm 12$ & $74 \pm 11$ & $79 \pm 12$ & $<0.01$ \\
\hline Male sex, n (\%) & $430(58)$ & $138(60)$ & $292(57)$ & 0.42 \\
\hline BMI $\left(\mathbf{k g} / \mathbf{m}^{2}\right)$ & $22 \pm 5$ & $21.7 \pm 5.7$ & $19.8 \pm 7.0$ & $<0.01$ \\
\hline Smoking history, n (\%) & $369(50)$ & $116(50)$ & $253(49)$ & 0.79 \\
\hline \multicolumn{5}{|l|}{ Heart disease } \\
\hline $\mathrm{DCM}, \mathrm{n}(\%)$ & $108(15)$ & $36(16)$ & $72(14)$ & 0.23 \\
\hline HCM, n (\%) & $33(4)$ & $8(4)$ & $25(5)$ & \\
\hline HHD, n (\%) & $51(7)$ & $16(7)$ & $35(7)$ & \\
\hline Ischemic heart disease, $\mathrm{n}(\%)$ & $180(24)$ & $53(23)$ & $127(25)$ & \\
\hline Diastolic dysfunction, n (\%) & $41(6)$ & $7(3)$ & $33(6)$ & \\
\hline Congenital heart disease, $\mathrm{n}(\%)$ & $31(4)$ & $15(7)$ & $16(3)$ & \\
\hline Atrial fibrillation, $\mathrm{n}(\%)$ & $76(10)$ & $21(9)$ & $56(57)$ & \\
\hline Valve disease, $\mathrm{n}(\%)$ & $178(24)$ & $57(25)$ & $121(24)$ & \\
\hline Other, n (\%) & $45(6)$ & $20(8)$ & $25(5)$ & \\
\hline \multicolumn{5}{|l|}{ Type of HF } \\
\hline HFpEF, n (\%) & $327(44)$ & $84(37)$ & $243(48)$ & $<0.01$ \\
\hline HFmrEF, n (\%) & $102(14)$ & $45(20)$ & $57(11)$ & \\
\hline HFrEF, n (\%) & $308(42)$ & $100(45)$ & $208(41)$ & \\
\hline \multicolumn{5}{|l|}{ Physical condition } \\
\hline LVEF, \% & $45.5 \pm 19.2$ & $43.3 \pm 18.7$ & $47.2 \pm 19.4$ & 0.28 \\
\hline BNP, pg/mL & $199[110-422]$ & $199[110-418]$ & $196[110-436]$ & 0.89 \\
\hline Hemoglobin, g/dL & $12.4 \pm 2.3$ & $12.3 \pm 2.3$ & $12.2 \pm 2.4$ & 0.33 \\
\hline BUN, mg/dL & $29.0 \pm 18.4$ & $29.6 \pm 19.3$ & $31.0 \pm 22.3$ & 0.36 \\
\hline Creatinine, mg/dL & $1.3 \pm 0.8$ & $1.3 \pm 0.7$ & $1.4 \pm 1.0$ & 0.16 \\
\hline Anaerobic threshold, $\mathrm{mL} / \mathrm{min} / \mathrm{kg}$ & $9.6 \pm 2.2$ & $9.9 \pm 2.3$ & $9.4 \pm 2.1$ & 0.15 \\
\hline Peak oxygen uptake, $\mathrm{mL} / \mathrm{min} / \mathrm{kg}$ & $13.2 \pm 3.5$ & $13.6 \pm 3.8$ & $12.8 \pm 3.3$ & 0.20 \\
\hline$\dot{V} E$ vs. $\dot{\mathrm{V} C O} 2$ slope & $39.8 \pm 9.2$ & $38.1 \pm 8.3$ & $40.4 \pm 9.8$ & 0.07 \\
\hline \multicolumn{5}{|l|}{ Medical history } \\
\hline Hypertension, n (\%) & $389(52)$ & $140(61)$ & $249(48)$ & $<0.01$ \\
\hline Diabetes mellitus, $\mathrm{n}(\%)$ & $215(29)$ & $69(28)$ & $146(28)$ & 0.63 \\
\hline Dyslipidemia, n (\%) & $242(33)$ & $90(39)$ & $152(30)$ & $<0.01$ \\
\hline COPD, n (\%) & $59(8)$ & $20(9)$ & $39(8)$ & 0.61 \\
\hline \multicolumn{5}{|l|}{ Medications } \\
\hline ACEI, n (\%) & $142(19)$ & $48(21)$ & $94(18)$ & 0.39 \\
\hline ARB, n (\%) & 277 (37) & $85(37)$ & $192(37)$ & 0.92 \\
\hline$\beta$-blocker, n (\%) & $529(71)$ & $183(80)$ & 347 (68) & $<0.01$ \\
\hline MRA, n (\%) & $333(45)$ & $117(51)$ & $216(42)$ & 0.02 \\
\hline SGLT2-I, n (\%) & $77(10)$ & $31(14)$ & $46(9)$ & 0.06 \\
\hline Loop diuretics, n (\%) & $615(83)$ & $190(83)$ & $425(83)$ & 0.92 \\
\hline Thiazide, n (\%) & $47(6)$ & $12(5)$ & $35(7)$ & 0.41 \\
\hline Tolvaptan, n (\%) & $186(25)$ & $64(28)$ & $122(24)$ & 0.22 \\
\hline Digitalis, n (\%) & $35(5)$ & $10(4)$ & $25(5)$ & 0.76 \\
\hline Participation in outpatient CR, $\mathrm{n}(\%)$ & $86(12)$ & $54(24)$ & $32(6)$ & $<0.01$ \\
\hline
\end{tabular}

${ }^{*}$ Group SRC(+) vs. SRC(-). All data are expressed as mean \pm standard deviation, median (25-75th percentiles), or frequency (percentage). The data were analyzed using Student's t-test, the chi-square test, and the Mann-Whitney $\mathrm{U}$ test, as appropriate. A $\mathrm{P}$ value $<0.05$ indicates statistical significance. ACEl, angiotensin-converting enzyme inhibitor; ARB, angiotensin II receptor blocker; BMI, body mass index; BNP, B-type natriuretic peptide; BUN, blood urea nitrogen; COPD, chronic obstructive pulmonary disease; CR, cardiac rehabilitation; DCM, dilated cardiomyopathy; HCM, hypertrophic cardiomyopathy; HHD, hypertensive heart disease; LVEF, left ventricular ejection fraction; MRA, mineralocorticoid receptor antagonist; SGLT2-I, sodium-glucose cotransporter 2-inhibitor; SRC, sodium restriction counseling; $\dot{V} E$, minute ventilation; $\dot{V} \mathrm{CO}_{2}$, carbon dioxide production. Type of heart failure (HF); $\mathrm{HFrEF}, \mathrm{HF}$ with reduced LVEF $(\mathrm{LVEF}<40 \%)$. HFpEF, HF with preserved LVEF (LVEF $\geq 50 \%)$. HFmrEF, HF with mid-range LVEF $(40 \% \leq L V E F<50 \%)$. 
Table 2. Cardiac Events and Sodium Restriction Counseling

\begin{tabular}{lcccc}
\multicolumn{1}{c}{ Event } & $\begin{array}{c}\text { SRC group } \\
(\mathbf{n = 2 2 9})\end{array}$ & $\begin{array}{c}\text { Non-SRC group } \\
(\mathbf{n = 5 1 4 )}\end{array}$ & OR (95\% CI) & P value \\
All-cause death & 14 & 69 & $0.42(0.23-0.76)$ & $<0.01$ \\
(Cardiac death & 9 & 57 & $0.33(0.16-0.68)$ & $<0.01)$ \\
HF rehospitalization & 43 & 110 & $0.85(0.57-1.26)$ & 0.43 \\
HF rehospitalization and all-cause death & 49 & 135 & $0.76(0.53-1.11)$ & 0.17 \\
\hline
\end{tabular}

Chi-square test, $\mathrm{P}<0.05$ indicates statistical significance. $\mathrm{Cl}$, confidence interval; $\mathrm{HF}$, heart failure; OR, odds ratio; SRC, sodium restriction counseling.

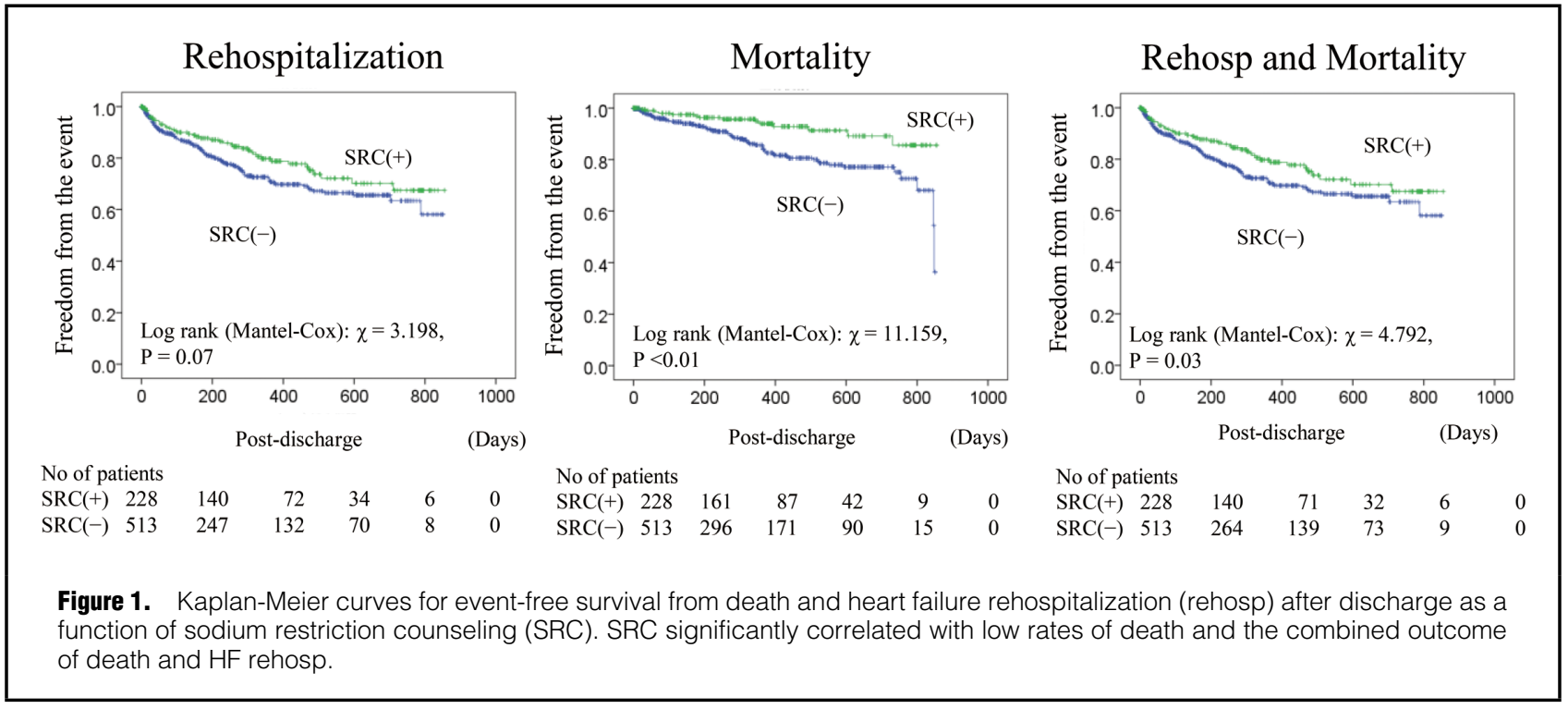

\begin{tabular}{|c|c|c|c|c|c|c|}
\hline \multirow{3}{*}{ Variable } & \multirow{2}{*}{\multicolumn{2}{|c|}{ Univariate analysis }} & \multicolumn{4}{|c|}{ Multivariate analysis } \\
\hline & & & \multicolumn{2}{|c|}{ Model 1} & \multicolumn{2}{|c|}{ Model 2} \\
\hline & OR $(95 \% \mathrm{Cl})$ & $P$ value & OR (95\% Cl) & $P$ value & OR (95\% Cl) & $P$ value \\
\hline Age & $1.029(1.007-1.052)$ & $<0.01$ & $1.025(1.002-1.048)$ & 0.03 & $1.038(1.011-1.065)$ & $<0.01$ \\
\hline Sex & $0.880(0.552-1.404)$ & 0.59 & $1.066(0.651-1.746)$ & 0.79 & $0.972(0.579-1.610)$ & 0.59 \\
\hline SRC & $0.501(0.295-0.850)$ & 0.01 & $0.438(0.235-0.817)$ & 0.03 & $0.501(0.295-0.850)$ & 0.01 \\
\hline BMI & $0.991(0.956-1.026)$ & 0.59 & & & $1.025(0.983-1.069)$ & 0.25 \\
\hline Hypertension & $0.450(0.278-0.731)$ & $<0.01$ & & & $0.453(0.272-0.754)$ & $<0.01$ \\
\hline Dyslipidemia & $0.525(0.300-0.919)$ & 0.02 & & & $0.637(0.357-1.137)$ & 0.31 \\
\hline$\beta$-blockers & $0.771(0.471-1.263)$ & 0.31 & & & $0.842(0.496-1.429)$ & 0.84 \\
\hline MRA & $0.847(0.529-1.356)$ & 0.48 & & & $0.845(0.515-1.384)$ & 0.51 \\
\hline CR & $0.373(0.133-1.046)$ & 0.06 & & & $0.691(0.233-2.047)$ & 0.51 \\
\hline Type of HF & $0.849(0.660-1.091)$ & 0.21 & & & $0.699(0.526-0.929)$ & 0.01 \\
\hline
\end{tabular}

$\mathrm{P}<0.05$ was statistically significant. Other abbreviations as in Tables 1,2 . Type of HF: HFrEF (LVEF $<40 \%)$ as number 1 , HFmrEF $(40 \% \leq \mathrm{LVEF}<50 \%)$ as number $2, \mathrm{HFpEF}(\mathrm{LVEF} \leq 50 \%)$ as number 3.

idemia, $\beta$-blockers, MRA intake, cardiac rehabilitation, and type of HF, SRC remained a significant predictor (Table 3).

\section{Type of HF and SRC}

Only in patients with HFrEF did SRC significantly decrease mortality (OR, 0.27; 95\% CI, 0.10-0.71; $\mathrm{P}<0.01$ ). Kaplan-Meier analysis showed that in patients with $\mathrm{HFrEF}$, SRC significantly reduced mortality during fol- low-up (log-rank $\left.\mathrm{X}^{2}, 7.671 ; \mathrm{P}<0.01\right)($ Figure 2).

\section{Factors Affecting SRC}

Although the percent decrease in estimated sodium intake was not significantly different with or without SRC $[\mathrm{SRC}(+)$ : $86.3 \pm 35.9$ vs. $\mathrm{SRC}(-): 77.4 \pm 28.9 \%, \mathrm{P}=0.55]$, the estimated sodium intake was significantly decreased after discharge (on admission; $12.1 \pm 3.8$ vs. follow-up; $9.8 \pm 4.3 \mathrm{~g} / \mathrm{day}$, 

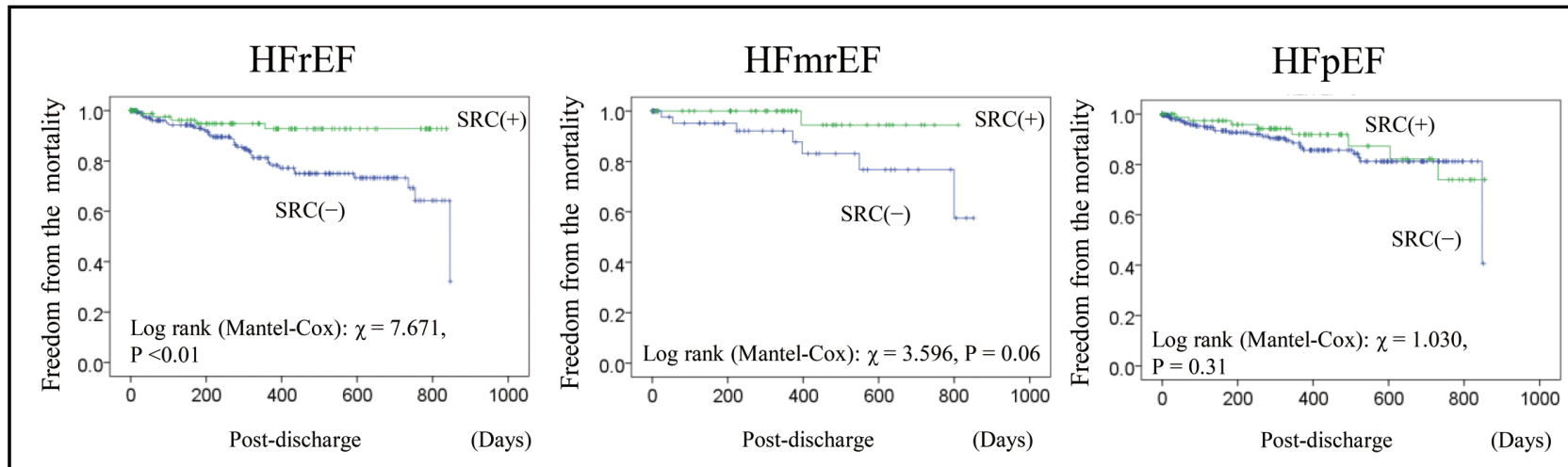

$\begin{array}{lrrrrr}\text { No of patients } & & & & & \\ \text { SRC (+) 99 } & 63 & 38 & 16 & 3 & 0 \\ \text { SRC(-) } 207 & 135 & 72 & 41 & 6 & 0\end{array}$

$\begin{array}{lllllll}\begin{array}{l}\text { No of patients } \\ \text { SRC(+) }\end{array} & 44 & 38 & 17 & 8 & 1 & 0 \\ \text { SRC(-) } & 56 & 30 & 18 & 9 & 3 & 0\end{array}$

\begin{tabular}{|c|c|c|c|c|}
\hline No of patients & & & & \\
\hline $\mathrm{SRC}(+) 83$ & 61 & 31 & 16 & 5 \\
\hline $\mathrm{SRC}(-) 242$ & 129 & 80 & 39 & 4 \\
\hline
\end{tabular}

Figure 2. Kaplan-Meier curves for event-free survival from death with or without sodium restriction counseling (SRC) as a function of left ventricular ejection fraction (LVEF). SRC was only significantly correlated with low rates of mortality in patients with heart failure with reduced LVEF (HFrEF) (LVEF<40\%). HFpEF, HF with preserved LVEF (LVEF $\geq 50 \%)$. HFmrEF, HF with mid-range EF $(40 \% \leq$ LVEF $<50 \%)$.

$\mathrm{P}<0.01$ ) independent of SRC.

On the other hand, Kaplan-Meier analysis showed that patients in the non-active stages of the TTM had significantly decreased mortality rate compared with active-stage patients (log-rank $\left.\mathrm{X}^{2}, 6.048 ; \mathrm{P}=0.01\right)$, and $\mathrm{SRC}(-)(\log -$ rank $\mathrm{X}^{2}, 12.505$; $\mathrm{P}<0.01$ ) (Figure 3).

\section{Discussion}

In this study, SRC significantly reduced the mortality rate of patients with HF after discharge, especially in patients with HFrEF. To the best of our knowledge, this is the first report to show that nutritional therapy is significantly effective in patients with HF, especially when delivered by registered dietitians.

The number of HF patients is significantly increasing worldwide and in Japan., ${ }^{\mathbf{1} 2}$ The mortality rate of HF is high, and about $25 \%$ of patients with $\mathrm{HF}$ die within 1 year after discharge. The hospital death rate was $4.7 \%$, and the 1-year mortality rate after HF hospitalization was $23.3 \%$ according to 3 large Japanese HF registries. ${ }^{5}$ The rehospitalization rate within 1 year was also high $(24.4-27.1 \%)$ in the WET-HF, ${ }^{3}$ ATTEND, ${ }^{4}$ and REALITY-AHF studies. ${ }^{6}$ Moreover, compared with the CHART-1 (2004), CHART-2 study (2010) suggests the percentage of HFpEF was higher than before. ${ }^{18}$ In this study, the consecutive HF-hospitalized patients had a mean age of 77 years, and $58 \%$ of the patients were male. The hospital death rate was $4.7 \%$, and the 1-year mortality and rehospitalization rates after discharge were $11 \%$ and $26 \%$, respectively. The percentage of $\mathrm{HFpEF}$ was $44 \%$. These characteristics were consistent with the patient characteristics and outcomes reported by Shiraishi et al. (mean age, 77 years; $56 \%$ male patients). ${ }^{5}$

The Japanese Circulation Society (JCS), ${ }^{7}$ European Society of Cardiology (ESC), ${ }^{8}$ and American Heart Association (AHA) HF guidelines ${ }^{9}$ recommend sodium restriction for all the patients with HF. The AHA guideline suggests $\leq 3 \mathrm{~g}$ /day of sodium intake as the target; most Americans eat $\geq 4 \mathrm{~g}$ /day of sodium. ${ }^{9}$ The JCS and ESC guidelines recommend $\leq 6 \mathrm{~g} /$ day of salt intake. ${ }^{7,8}$ Japanese

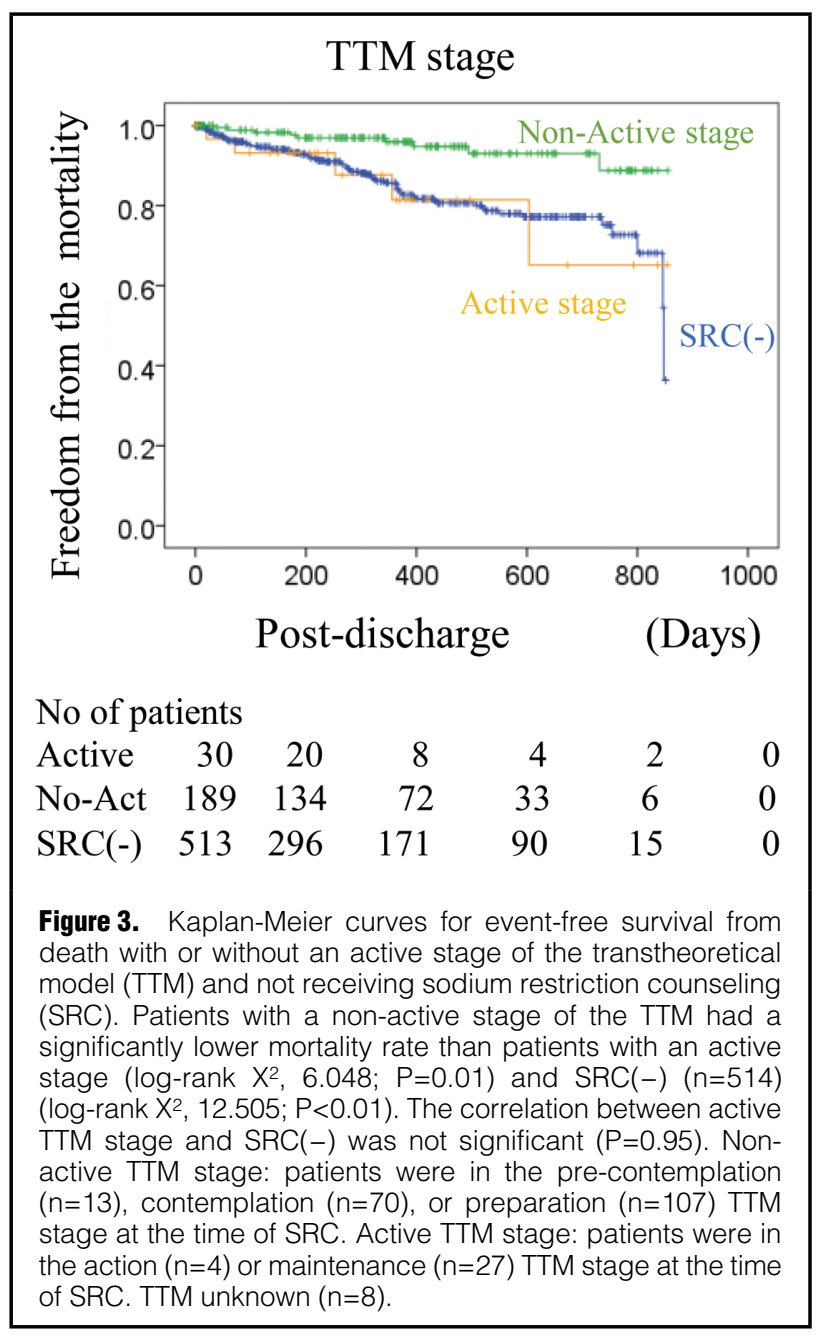

Circulation Journal Vol.85, September 2021 
generally eat higher amounts of salt. ${ }^{19}$ In a national report, the mean salt intake in Japan was $10.1 \mathrm{~g} /$ day. ${ }^{20}$ Some countries report a salt intake $>10 \mathrm{~g} / \mathrm{day}$, and the average salt intake worldwide is $6 \mathrm{~g} / \mathrm{day} .{ }^{21}$ There are several randomized studies of sodium restriction. 22-30 Lower sodium intake decreases the rate of acute decompaction $\mathrm{HF},{ }^{22,27}$ and other studies favor sodium restriction because it is associated with a decrease in hypertension due to decreased activity of the renin-angiotensin-aldosterone system (RAAS). ${ }^{\mathbf{2 3 - 2 6}}$ However, $<2.5 \mathrm{mg} /$ day of sodium intake is harmful in patients with $\mathrm{HF},{ }^{28}$ and some studies suggest that it is unfavorable because sodium restriction decreases intravascular volume contraction and increase RAAS and neurological hormones. ${ }^{29,30}$ Although many HF guidelines highly recommend sodium restriction for patients with $\mathrm{HF}$, the evidence is still debatable. ${ }^{23}$ Because sodium intake is higher in Japan than in many other countries, the effectiveness of sodium restriction therapy may differ.

In this study, patients with HF were given SRC during hospitalization for at least $30 \mathrm{~min}$ to encourage a reduction in salt intake to $<6 \mathrm{~g} /$ day after discharge. Some patients were instructed to cook their meals with their families. Although there are many positive clinical trials on salt restriction, ${ }^{22-27}$ in the real-world, SRC is not a salt restriction clinical trial. SRC consists of salt restriction and counseling. In this study, we observed that in both patients with and without SRC, salt intake after discharge was reduced. Because all patients hospitalized with HF had a diet with $<6$ g/day of salt and were educated in HF lifestyle modification by the nursing care team during the hospitalization, these effectiveness is assumed. On the other hand, although the patients who had already begun to reduce their salt intake did not improve their mortality rate, those who had no or low motivation for salt restriction did improved their mortality rate after undergoing SRC (Figure 3). This suggests that the effects of SRC on the HF patients' behavior were due to the newly realized necessity for salt restriction. Vollone et al have reported that nurses' motivational counsel improves patients' self-care management and its maintenance. ${ }^{31}$ Jonkman et al have also reported that selfcare reduced deaths of patients with $\mathrm{HF}$ in their metaanalysis. Most counseling was performed by a nurse, physician, or cardiologist, and some studies included telephone call support after counseling. ${ }^{32}$ In this study registered dietitians performed only one-time counseling based on the TTM, which has been used to change the eating behaviors of patients with type 2 or to generally increase the vegetable and fruit intake of patients. ${ }^{17,33,34}$ When HF patients in the "pre-contemplation" or "contemplation" stage were counseled, the focus was on listening and not making many suggestions. When HF patients in the "preparation" stage were counseled, specific goals were presented. The HF patients in the "action" or "maintenance" stage were counseled to maintain their behavior. Thus, the TTM varies the approach to salt reduction depending on the patient's behavioral stage. Tailoring the TTM-based counseling to the patient's motivational stage leads to continuation of motivational modification for salt reduction.

The study results suggested that adding SRC-tailored TTM by registered dietitians to usual care was the main reason for the motivational modification of salt reduction and improved HF mortality in this study (OR 0.42; 95\% CI $0.23-0.76$ ).

In previous reports, sodium restriction studies were only conducted for HFrEF, ${ }^{22,35,36}$ and occasionally, HFmrEF. ${ }^{26}$ Machado d'Almeida et al attempted aggressive sodium reduction therapy in patients with $\mathrm{HFpEF} ;{ }^{37}$ although HFpEF correlates with hypertension, their results were not significantly different between patients who were managed with sodium restriction and those without. In our study, a significant reduction in deaths after discharge was observed for patients with $\mathrm{HFrEF}$, which is similar to the findings reported in previous studies.

In the multiple logistic analysis (Table 3), in addition to SRC, age, hypertension, and HFrEF were the predictors of death. Aging is one of the major predictors of death in patients with heart disease. According model 1 in Table 3, the death of patients with HF increases by $3.8 \%$ each year. However, SRC decreased the mortality rate by $49.9 \%$, which suggests that SRC is worth $13(49.9 / 3.8)$ years. In model 2, age, hypertension, and HFrEF were significant predictors in addition to SRC. Patients with hypertension had higher systolic blood pressure $(114 \pm 18$ vs. $106 \pm 20 \mathrm{mmHg}$, $\mathrm{P}<0.01)$ and ACEI/ARB intake $(70.2 \%$ vs. $39.7 \%, \mathrm{P}<0.01)$ in this study. HF patients with hypotension have a significantly higher risk for mortality, ${ }^{\mathbf{3 8}}$ and treatment for hypertension is similar to that for $\mathrm{HF}$, including $\beta$-blockers or ACEI/ARBs. In this study, higher systolic blood pressure and use of ACEI/ARBs might have affected the hypertension history. In previous studies, patients with HFrEF (LVEF $27 \pm 7 \%, 66 \pm 13$ years) or HFpEF (LVEF 62 $\pm 9 \%$, $73 \pm 12$ years) had similar mortality rates. ${ }^{39}$ However, in our study, patients with HFrEF (LVEF 26 [19-33]\%, 72 13 years) had a higher OR than those with HFpEF(LVEF 60 [55-65]\%, 81 \pm 10 years). Compared with previous studies, our patients with HFrEF were older. Moreover, they had longer hospitalization periods than the patients with HFpEF (15 [9-23] vs. 13 [8-22] days, $\mathrm{P}<0.04)$. Patients with HFrEF seemed to have a more severe condition than did patients with HFpEF during hospitalization. These different patient characteristics and conditions might have affected the mortality difference between the patients with HFrEF and HFpEF.

Sodium-glucose cotransporter-2 inhibitors (SGLT2I) have been used to treat HF based on both randomized studies and real-world data. ${ }^{\mathbf{4 0 , 4 1}}$ Although there are some randomized studies of sodium restriction therapy, ${ }^{22-27}$ realworld reports are rare. This study showed favorable data for sodium restriction therapy in patients with $\mathrm{HF}$, which supports the reduction in mortality rates after hospitalization in real-world data analyses.

In conclusion, SRC significantly reduced the mortality rate in patients hospitalized with $\mathrm{HF}$, and SRC was the most effective therapy for patients with HFrEF. SRC is an easy, cheaper, and highly efficacious choice for reducing HF mortality. Spreading awareness regarding the effectiveness of SRC might reduce the rate of rehospitalization in patients with $\mathrm{HF}$.

\section{Study Limitation}

This was a single-center study with a relatively small number of patients. Future multicenter studies are needed to confirm our findings. However, SRC is much cheaper than any other therapy (2,600 yen [24 dollars/20 euros]) and the reduction in the mortality rate was notable.

\section{Acknowledgment}

We thank the nutrition team at our hospital for preparing food and daily counseling of patients. 


\section{Disclosures}

This research received no specific grant from any funding agency in the public, commercial, or not-for-profit sectors. The authors have no competing interests to declare.

\section{IRB Information}

The study was conducted according to the Japanese ethical rules and was approved by the Ethics Committee of the Gunma Prefectural Cardiovascular Centre (no. 2020015).

\section{References}

1. Virani SS, Alonso A, Benjamin EJ, Bittencourt MS, Callaway CW, Carson AP, et al. Heart Disease and Stroke Statistics-2020 Update: A report from the American Heart Association. Circulation 2020; 141: e139-e596.

2. Okura Y, Ramadan MM, Ohno Y, Mitsuma W, Tanaka K, Ito $\mathrm{M}$, et al. Impending epidemic: Future projection of heart failure in Japan to the year 2055. Circ J 2008; 72: 489-491.

3. Shiraishi Y, Kohsaka S, Abe T, Mizuno A, Goda A, Izumi Y, et al. Validation of the Get With The Guideline-Heart Failure risk score in Japanese patients and the potential improvement of its discrimination ability by the inclusion of B-type natriuretic peptide level. Am Heart J 2016; 171: 33-39.

4. Sato N, Kajimoto K, Asai K, Mizuno M, Minami Y, Nagashima $\mathrm{M}$, et al. Acute decompensated heart failure syndromes (ATTEND) registry: A prospective observational multicenter cohort study: Rationale, design, and preliminary data. Am Heart J 2010; 159: 949-955.e1.

5. Shiraishi Y, Kohsaka S, Sato N, Takano T, Kitai T, Yoshikawa $\mathrm{T}$, et al. 9-year trend in the management of acute heart failure in Japan: A report from the National Consortium of Acute Heart Failure Registries. J Am Heart Assoc 2018; 7: e008687.

6. Matsue Y, Damman K, Voors AA, Kagiyama N, Yamaguchi T, Kuroda S, et al. Time-to-furosemide treatment and mortality in patients hospitalized with acute heart failure. J Am Coll Cardiol 2017; 69: 3042-3051.

7. Tsutsui $\mathrm{H}$, Isobe $\mathrm{M}$, Ito $\mathrm{H}$, Ito $\mathrm{H}$, Okumura $\mathrm{K}$, Ono $\mathrm{M}$, et al; on behalf of the Japanese Circulation Society and the Japanese Heart Failure Society Joint Working Group. JCS 2017/JHFS 2017 guideline on diagnosis and treatment of acute and chronic heart failure: Digest version. Circ J 2019; 83: 2084-2184.

8. Ponikowski P, Voors AA, Anker SD, Bueno H, Cleland JGF, Coats AJS, et al. 2016 ESC Guidelines for the diagnosis and treatment of acute and chronic heart failure: The Task Force for the Diagnosis and Treatment of Acute and Chronic Heart Failure of the European Society of Cardiology (ESC) developed with the special contribution of the Heart Failure Association (HFA) of the ESC. Eur Heart J 2016; 37: 2129-2200.

9. Writing Committee Members, Yancy CW, Jessup M, Bozkurt B, Butler J, Casey DE Jr, Drazner MH, et al. 2013 ACCF/AHA guideline for the management of heart failure: A report of the American College of Cardiology Foundation/American Heart Association Task Force on practice guidelines. Circulation 2013; 128: e $240-\mathrm{e} 327$

10. Nagueh SF, Smiseth OA, Appleton CP, Byrd BF 3rd, Dokainish $\mathrm{H}$, Edvardsen T, et al. Recommendations for the Evaluation of Left Ventricular Diastolic Function by Echocardiography: An Update from the American Society of Echocardiography and the European Association of Cardiovascular Imaging. J Am Soc Echocardiogr 2016; 29: 277-314.

11. Nakatani S, Akaishi M, Asanuma T, Hashimoto S, Izumi C, Iwanaga S, et al. Guidelines from the Japanese Society of Echocardiography: Guidance for the management and maintenance of echocardiography equipment. $J$ Echocardiogr 2015; 13: 1-5.

12. Buchfuhrer MJ, Hansen JE, Robinson TE, Sue DY, Wasserman $\mathrm{K}$, Whipp BJ. Optimizing the exercise protocol for cardiopulmonary assessment. $J$ Appl Physiol Respir Environ Exerc Physiol 1983; 55: 1558-1564.

13. Borg G. Perceived exertion as an indicator of somatic stress. Scand J Rehabil Med 1970; 2: 92-98.

14. Beaver WL, Wasserman K, Whipp BJ. Bicarbonate buffering of lactic acid generated during exercise. J Appl Physiol (1985) 1986; 60: $472-478$.

15. Stringer W, Casaburi R, Wasserman K. Acid-base regulation during exercise and recovery in humans. J Appl Physiol 1992; 72: 954-961.

16. Tanaka T, Okamura T, Miura K, Kadowaki T, Ueshima H,
Nakagawa H, et al. A simple method to estimate populational 24-h urinary sodium and potassium excretion using a casual urine specimen. J Hum Hypertens 2002; 16: 97-103.

17. Prochaska JO, Velicer WF. The transtheoretical model of health behavior change. Am J Health Promot 1997; 12: 38-48.

18. Shiba N, Watanabe J, Shinozaki T, Koseki Y, Sakuma M, Kagaya $\mathrm{Y}$, et al. Analysis of chronic heart failure registry in the Tohoku district: Third year follow-up. Circ J 2004; 68: 427-434.

19. Brown IJ, Tzoulaki I, Candeias V, Elliott P. Salt intakes around the world: Implications for public health. Int J Epidemiol 2009; 38: $791-813$.

20. Ministry of Health, Labour and Welfare, Japan. Kokumin Kenkou Eiyoutyosa (in Japanese). Report. The Ministry, Tokyo, Japan, 2018.

21. Thout SR, Santos JA, McKenzie B, Trieu K, Johnson C, McLean R, et al. The Science of salt: Updating the evidence on global estimates of salt intake. J Clin Hypertens (Greenwich) 2019; 21: 710-721.

22. Arcand J, Ivanov J, Sasson A, Floras V, Al-Hesayen A, Azevedo $\mathrm{ER}$, et al. A high-sodium diet is associated with acute decompensated heart failure in ambulatory heart failure patients: A prospective follow-up study. Am J Clin Nutr 2011; 93: 332-337.

23. Khan MS, Jones DW, Butler J. Salt, no salt, or less salt for patients with heart failure? Am J Med 2020; 133: 32-38.

24. Colin Ramirez E, Castillo Martinez L, Orea Tejeda A, Rebollar Gonzalez V, Narvaez David R, Asensio Lafuente E. Effects of a nutritional intervention on body composition, clinical status, and quality of life in patients with heart failure. Nutrition 2004; 20: 890-895.

25. Sacks FM, Svetkey LP, Vollmer WM, Appel LJ, Bray GA, Harsha $\mathrm{D}$, et al. Effects on blood pressure of reduced dietary sodium and the Dietary Approaches to Stop Hypertension (DASH) diet: DASH-Sodium Collaborative Research Group. $N$ Engl J Med 2001; 344: 3-10.

26. Volpe M, Tritto C, DeLuca N, Rubattu S, Rao MA, Lamenza $\mathrm{F}$, et al. Abnormalities of sodium handling and of cardiovascular adaptations during high salt diet in patients with mild heart failure. Circulation 1993; 88: 1620-1627.

27. Licata G, Di Pasquale P, Parrinello G, Cardinale A, Scandurra A, Follone G, et al. Effects of high-dose furosemide and smallvolume hypertonic saline solution infusion in comparison with a high dose of furosemide as bolus in refractory congestive heart failure: Long-term effects. Am Heart J 2003; 145: 459-466.

28. Doukky R, Avery E, Mangla A, Collado FM, Ibrahim Z, Poulin $\mathrm{MF}$, et al. Impact of dietary sodium restriction on heart failure outcomes. JACC Heart Fail 2016; 4: 24-35.

29. Damgaard M, Norsk P, Gustafsson F, Kanters JK, Christensen $\mathrm{NJ}$, Bie $\mathrm{P}$, et al. Hemodynamic and neuroendocrine responses to changes in sodium intake in compensated heart failure. Am $J$ Physiol Regul Integr Comp Physiol 2006; 290: R1294-R1301.

30. Paterna S, Parrinello G, Cannizzaro S, Fasullo S, Torres D, Sarullo FM, et al. Medium term effects of different dosage of diuretic, sodium, and fluid administration on neurohormonal and clinical outcome in patients with recently compensated heart failure. Am J Cardiol 2009; 103: 93-102.

31. Vellone E, Rebora P, Ausili D, Zeffiro V, Pucciarelli G, Caggianelli $\mathrm{G}$, et al. Motivational interviewing to improve self-care in heart failure patients (MOTIVATE-HF): A randomized controlled trial. ESC Heart Fail 2020; 7: 1309-1318.

32. Jonkman NH, Westland H, Groenwold RH, Agren S, Atienza $\mathrm{F}$, Blue $\mathrm{L}$, et al. Do self-management interventions work in patients with heart failure?: An individual patient data metaanalysis. Circulation 2016; 133: 1189-1198.

33. Di Noia J, Prochaska JO. Mediating variables in a transtheoretical model dietary intervention program. Health Educ Behav 2010; 37: 753-762.

34. Carvalho de Menezes M, Bedeschi LB, Santos LC, Lopes AC. Interventions directed at eating habits and physical activity using the Transtheoretical Model: A systematic review. Nutr Hosp 2016; 33: 586.

35. Philipson H, Ekman I, Forslund HB, Swedberg K, Schaufelberger M. Salt and fluid restriction is effective in patients with chronic heart failure. Eur J Heart Fail 2013; 15: 1304-1310.

36. Burgermaster M, Rudel R, Seres D. Dietary sodium restriction for heart failure: A systematic review of intervention outcomes and behavioral determinants. Am J Med 2020; 133: 1391-1402.

37. Machado d'Almeida KS, Rabelo-Silva ER, Souza GC, Trojahn MM, Santin Barilli SL, Aliti G, et al. Aggressive fluid and sodium restriction in decompensated heart failure with preserved ejection fraction: Results from a randomized clinical trial. Nutri- 
tion 2018; 54: 111-117.

38. Miura M, Sakata Y, Miyata S, Nochioka K, Takada T, Tadaki $\mathrm{S}$, et al. Usefulness of combined risk stratification with heart rate and systolic blood pressure in the management of chronic heart failure: A report from the CHART-2 study. Circ J 2013; 77: $2954-2962$.

39. Tsuchihashi-Makaya M, Hamaguchi S, Kinugawa S, Yokota T, Goto D, Yokoshiki H, et al. Characteristics and outcomes of hospitalized patients with heart failure and reduced vs. preserved ejection fraction: Report from the Japanese Cardiac Registry of Heart Failure in Cardiology (JCARE-CARD). Circ J 2009; 73:
$1893-1900$

40. Kosiborod M, Cavender MA, Fu AZ, Wilding JP, Khunti K, Holl RW, et al. Lower risk of heart failure and death in patients initiated on sodium-glucose cotransporter-2 inhibitors versus other glucose-lowering drugs: The CVD-REAL study (Comparative Effectiveness of Cardiovascular Outcomes in New Users of Sodium-Glucose Cotransporter-2 Inhibitors). Circulation 2017; 136: 249-259.

41. Zinman B, Wanner C, Lachin JM, Fitchett D, Bluhmki E, Hantel $\mathrm{S}$, et al. Empagliflozin, cardiovascular outcomes, and mortality in type 2 diabetes. $N$ Engl J Med 2015; 373: 2117-2128. 